\title{
Bilingual Teaching Exploration and Practice of Engineering Materials and Fundamental of Mechanical Manufacture for the Context of Excellent Engineers
}

\author{
Bolin $\mathrm{He}^{\mathrm{a},{ }^{*}}$, Zhaoxia Chen ${ }^{\mathrm{b}}$ and Zhisen Zhang ${ }^{\mathrm{c}}$
}

School of Mechanical \& Electrical Engineering, East China Jiaotong University, Nanchang, Jiangxi, 330013, China

ahebolin@163.com, bczx79@126.com, ${ }^{\mathrm{c}} 254388550 @ q q . c o m$

Keywords: Bilingual teaching; Excellent engineers; Teaching reform; Engineering materials; Fundamental of mechanical manufacture

\begin{abstract}
Based on mechanical engineering specialty of "excellent engineer training plan" as the guidance, combined with engineering materials and machinery basic course characteristics, put forward from the change the teaching idea, write Bilingual teaching book, selection of bilingual teaching content, to reform the experiment teaching content and methods, strengthening bilingual teaching literacy, team construction and teaching quality control, and so on. The exploration and practice of bilingual teaching course of Engineering Materials and Fundamentals of Mechanical Manufacture was carried out. To improve the students' practical ability, strengthen innovation consciousness, and cultivate excellent mechanical engineer laid a foundation.
\end{abstract}

\section{Introduction}

Engineering Materials and Fundamentals of Mechanical Manufacture is a compulsory specialized basic course for mechanical major, nearly machine and the non-machine can also be professional courses. Undergraduate course teaching should create conditions to use English to carry on the pubic course and specialized course teaching that put forward by the Department of Education in 2011. Relevant national curriculum guide team points out: Engineering Materials and Fundamentals of Mechanical Manufacture is not only a compulsory technical basic course of technology and engineering practice lesson, and it is an intersecting field of multi-subjects which is closely relating to the social human studies and management science. Since 2004, the authors and course group have been a bilingual teaching to Engineering Materials and Fundamentals of Mechanical Manufacture for material shaping and control engineering specialty in our school, and we have accumulated nearly 10 years of experience in bilingual teaching. Since 2011, the specialty of mechanical engineering of our university was identified as experimental specialty in "excellent engineer training plan", and training plan will be the courses of Engineering Materials and Fundamentals of Mechanical Manufacture as bilingual education programs [1]. This course is an important part of education of mechanical engineering materials, modern manufacturing methods and process technology base for students, is an engineering practice training for students. The course is particularly important in the status of excellent engineers education, which has other irreplaceable important role to improve the comprehensive quality of future outstanding engineers and cultivate senior engineering talents.

\section{Curriculum characteristic}

The course of Engineering Materials and Fundamentals of Mechanical Manufacture involving wide knowledge,such as metal materials,polymer materials,ceramics materials,composite materials, the microstructure and properties of materials, heat treatment of steel, etc. In addition, machining process of the course covers the casting, forging, welding, machining and special processing and so on, each part involves a professional discipline. The curriculum content system of engineering materials and 
fundamental of mechanical manufacture has been greatly enriched with the new technology, new materials and new technology constantly emerging [2].

The course has the following four characteristics: first, it is difficult to learn for students with its abstract theory that involves crystal structure and crystallization, plastic deformation and recrystallization, heat treatment principles and phase, etc. Second, the course have very strong practicality, which requires students have higher ability of hands-on practice.For example,the relationship between metal structure and mechanical properties need to students through experimental courses to improve; how to using heat treatment process for steel of different organizations also need students to deepen understanding through the experiment; Third, the content have a strong comprehensive.Students should learn to choose appropriate materials and design process according to stress distribution and performance of parts. Fourth, the content of the systemic and rigor is poorer, lack of rationality [3].

These characteristics have caused many problems of classroom teaching, such as the content of the narrative, more tedious. It is difficult to learn for student, there is inharmonious between teaching and learning.

\section{Discussion on teaching content reform}

Change the concept of teaching. In order to cultivate innovative excellence engineers, the teacher should set up the modernization of education, change the traditional instilling curricular teaching and enhance student's innovation ability as the central education [4]. Traditional teaching contents including the composition of material, materials manufacturing, material properties and performance is shown in Figure 1.

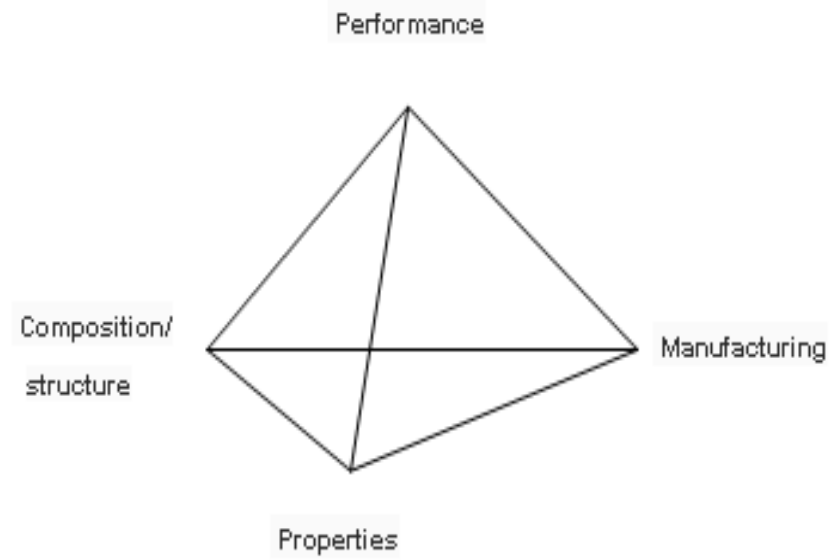

Figure. 1 Traditional contents and the relationship between them

Education is not only the means of training and instilling, but also the means of development and cognition. In the cognitive process, teachers should actively guide the student to participate in class discussion, attach importance to each student's individual differences, cultivate the students' learning initiative and creative ability of solve practical problems.Teacher should be encouraged such as discussion method, case-researching method, elicitation method, teach students the ability to gain knowledge [5-8]. In the teaching process, teachers should gradually lead the students to master the methods to solve problems, guide students participate in the exploration of teaching, enhance the subjective activity of students, cultivate the practicing ability and innovative thinking ability of students, which enable students to have a sense of achievement in learning.

Bilingual textbooks compilation and well-selected teaching content. First of all, we take some measures of teaching reform about Engineering Materials and Fundamentals of Mechanical Manufacture in material shaping and control engineering specialty, including the teaching outline and the content, according to the above characteristics of the course.Teaching outline and textbook content selection should fully embody the characteristics of talent cultivation and professional teaching [9]. 
Therefore, curriculum group have been written the teaching outline of Engineering Materials and Fundamentals of Mechanical Manufacture(bilingual), on the basis of sufficient investigation. At present, different versions of the Chinese materials retained the traditional mode and contents, in order to increase the latest research results of material science, course group have compiled the new textbooks of Engineering Materials and Fundamentals of Mechanical Manufacture(Chinese version), which have been published. There are two problems in manufacture technology and materials science and foundation, which is the internationally recognized. First, the system of contents of English original textbook is far from the Chinese textbook; second, students' learning activities can not be carried out smoothly, because of the limitation of students' English level. Therefore, in the course of teaching reform, we compiled the new bilingual textbooks of Engineering Materials and Fundamentals of Mechanical Manufacture.

The introduction of the case teaching method in the course of Engineering Materials and Fundamentals of Mechanical Manufacture teaching, which can implement the actual combination of theory with practice, allow us to understand a relatively complicated and abstract concept in terms of a more familiar and concrete concept, improve the efficiency of learning significantly. For example, in the interpretation of the heat treatment process,the teaching case of "Gear heat treatment" was designed. The heat treatment process steps and mechanical property of automobile transmission gear were described. In addition, how to arrange the heat treatment process to achieve the above requirements was introduced in detail. Therefore, it can be good at combining theory with practice, turning abstract into concrete, changing irritancy into lifelikeness, and the teaching effect of the course was improved.

The reform of experimental teaching content and methods. In order to cultivate students' comprehensive ability of applying knowledge, the experiment content and form of the course was reformed. The experiment was divided into basic skill experiment, comprehensive experiment and research experiment. Meanwhile, the classes were increased from 6 to 8 . The technology scheme of comprehensive experiment was drawn up independently by student team.For example, the three properties of material were measured in the minimum time, it required students make the preferable heat treatment parameters and process which was determined by consulting the relevant documents and materials. Students must answer the corresponding questions in the experiment report when experiment was completed. Such as: what is the theory basis of parameters and how to explain in the theory? In making scientific experiments, the technology scheme was drawn up by student team and teachers only need to put forward further need solving problem. The students were given the greatest independence and freedom of studying, which help to do exercises and train students' ability of the applied knowledge and independent learning through curriculum reform.

Strengthen the teaching quality and the construction of teachers' contingent. Serious lack of bilingual teachers has become a key factor for bilingual teaching that is difficult to promotion.Bilingual teaching is not only a challenge to students, but also to teachers, which requires the teacher both to master the disciplines of knowledge and have excellent English conversation skills and reading ability [10]. At present, the problem of lack of bilingual teachers can only be resolved through training. The young teachers were trained by some famous teachers and foreign teachers who were invited by university and have successful experiences, which achieved significant results. Moreover, the bilingual teachers were sent to English-speaking countries for short-term training (six months or a year), which would understand the subject frontiers, learn the advanced teaching method and improve English level.

The teachers who want to teach next semester must apply to participate in the Class Review that was organized by Academic Affairs Office in this semester. The expert panel has three components: foreign teachers, foreign language college teachers, professional teacher who study abroad for more than one year. The pronunciation, lectures, blackboard writing and professional knowledge of teacher would be a comprehensive test, and the teachers would pass the test when the total score more than 85 . 
Strict control on bilingual teaching in the high quality to complete the teaching mission play a key role. At present, the curriculum group has developed two young bilingual teachers, a teacher has 3 years of experience of bilingual teaching, another has 2 years of experience and completed the teaching in some chapters under the guidance of teachers.

The reform of teaching means and method. Heuristic teaching method were introduced to the course, which enumerated the vivid and specific case from production line,enrich the teaching content.For example, the content of metal heat treatment is monotonous, but it is closely linked to the production practice. The content of the metal parts processing, heat treatment process and heat treatment equipment were introduced by showing the multimedia courseware, which would stimulate students interest in learning and develop their perceptual knowledge. The video of heat treatment process that shoot in heat treatment workshop were put into the classroom, which could help students grasp the basic theory of heat treatment in short time.

The concept of abstract can be understood easily and complex organizations can be shown visually by using the modernizing teaching means and choosing the suit-able teaching ways. The thinking ability of students will be training by class discussions.Students' initiative and enthusiasm will be greatly improved when the form of International Conference was referenced in class. Besides, bilingual teachers should pay attention to combine the basic theory and advanced technology together, combine scientific research achievements and frontier information, so as to integrate theory with practice.

The introduction of multimedia teaching. Engineering Materials and Fundamentals of Mechanical Manufacture is the first specialized basic course of mechanical major. Plan B and original English teaching materials were used in bilingual teaching, because there are many basic concepts of professional and students learn English slowly, especially in the early stage of bilingual teaching. The key content of courses need to use English and Chinese to repeated explanation and emphasis, and normal teaching schedule would be delay due to the transformation of the two languages.

These problems can be solved through the multimedia teaching methods.Multimedia combination teaching program is an advanced teaching mode which appeared in recent years.Many kinds of electronic teaching means and traditional teaching methods are combined together,which designed each lesson,show different knowledge point by the proper teaching media to reach the teaching goal.Multimedia was applied in bilingual teaching of Engineering Materials and Fundamentals of Mechanical Manufacture, which can save a lot of time of blackboard writing and help students to learn spoken English.It is essential to build a rich material base that contains illustrations, graphics, animation, audio and video for a good multimedia courseware. Besides, it is a progressive work to make the teaching content more artistic. Teachers should follow the development trend of new material, new technology, new craft,close ties to the new information, new techniques, and use it to teaching. Teacher's abilities of observation and accumulating materials should be trained, if students want to make a better multimedia courseware.

Arousing the enthusiasm of classroom participation. It is the central task of teaching to arouse the students' enthusiasm and creativity of learning and cultivate students' ability of autonomous learning. Students would learn to use English to think about the problem, exchange ideas and acquire knowledge. Students would willing to participate in bilingual teaching and support for bilingual teaching reform, if they realize the importance and necessity of English.The students' English application ability couldn't be improved, if teacher use English in class, and students to use Chinese. Therefore, the bilingual teaching should be used in homework, classroom discussion and examination. Harmonious, equal classroom atmosphere and teaching situation of speak English, write English should be created, which remove students' shyness and lead students to use English to communicate with teachers and classmates. The emphasis and difficulty of curriculum should be informed in advance, which allow students to prepare in advance and increase the effectiveness in teaching greatly. Some related problems should be discussed in English after finishing the course. For example, each student was required to participate in the discussion in English for the course of Iron-carbon alloy 
phase diagram. Besides, some mistakes of pronunciation and grammar that students make would be corrected in time by teacher.

\section{Conclusion}

The ability to use English and read English original books and papers will be improved by bilingual teaching, which has a great help for the follow-up courses and graduate design. The reform of teaching mode and the quality of education will be improved greatly with bilingual teaching. The facts show that students' capability of solving practical problems was improved after having practiced for years. Students had a more profound understanding in selection of mechanical parts and processing technology through bilingual teaching and reading lots of original English literature. The multimedia courseware is a perfect combination of excellent teachers' wisdom and multimedia technology, which integrate content of courses with teaching means and teaching mode. The three-dimensional teaching makes an organic combination of the proper teaching method and the modern advanced education technology, doing a better job in elaborating its function and effect.

\section{Acknowledgment}

The research is supported by the pilot project of professional comprehensive reform of general undergraduate colleges and universities in Jiangxi province (No.2013GZC0028), High-quality goods resource sharing class in Jiangxi province (No.[2012]130) and Fine course construction project in Jiangxi province (No.[2011]74).

\section{References}

[1] Department of Education.Several Resolutions on Strengthening Teaching Work of Undergraduate Course and Heightening the Teaching Quality in Colleges and Universities. Beijing: Department of Education, 2001.

[2] Hou Yingke, Zhao Daxu, Cao Huanling, Xu Xiaofeng. Explore teaching reform of mechanical manufacturing basis. China Electric Power Education, 2013 (20): 68-69.

[3] Li Zhiyang, Huang Mingyu. Research and application of multimedia courseware of engineering materials and foundation of mechanical manufacturing course. Journal of Nantong Technology Institute (SOCIAL SCIENCE EDITION). 2004, 20(4):158-160.

[4] Cheng Fan,Wang Qing Sheng. Exploration and Practice of Course Software Engineering in the Context of Excellent Engineers.Computer knowledge and technology, 2011, 7(34):8976-8977.

[5] Wang Xiao Jing.The Development of Bilingual Education in China.Oversea English. 2012, (11):33-37.

[6] Zhao Hanyu, Wang Dong, Li Yundong. Research on the experimental teaching reform of mechanical engineering materials. Science and Technology Innovation Herald. 2010, 32 (3):245-248.

[7] Zhang Aimei. Discussion on teaching reform of the new period of the machinery manufacturing specialty practice. Education and Occupation, 2008, (26):39-42.

[8] Hou Yingke, Zhao Daxu, Cao Huanling, Xu Xiaofeng. Explore teaching reform of mechanical manufacturing basis. China Electric Power Education, 2013, 20 (3): 68-69.

[9] Ma Chang Long,Tianjin Normal University.Bilingual Teacher Training Is the Premise to the Starting of Bilingual Teaching. Teaching English in China. 2004, 9(03):17-21. 
[10] Zhao Song Mei, Ding Guo Yu. On Conditions of Bilingual Education.Oversea English. 2012, (11):12-16. 